\section{Diversidade funcional: a diferença e o histórico modelo de homem-padrão}

\section{Differently abled: difference and the historical model of the standard man}

\section{Ray Pereira}

Psicólogo; doutor em saúde pública (ENSP/Fiocruz) Rua General Roca, 826/702

20521-070 - Rio de Janeiro - RJ - Brasil p.raypereira@gmail.com

Recebido para publicação em março de 2008. Aprovado para publicação em maio de 2009.
PEREIRA, Ray. Diversidade funcional: a diferença e o histórico modelo de homem-padrão. História, Ciências, Saúde - Manguinhos, Rio de Janeiro, v.16, n.3, jul.-set. 2009, p.715-728.

\section{Resumo}

Analisa criticamente as formas como a diferença notada nas pessoas com deficiência foi percebida e tratada, desde a Antiguidade, nos âmbitos social, educacional político e terapêutico, até alcançar as mudanças observadas no país em décadas recentes. Para designar as pessoas com deficiência, independentemente do tipo ou grau da deficiência, utilizam-se os termos 'diversidade funcional' e 'diferença funcional', que não enfatizam os aspectos negativos, comum na terminologia vigente. Com base em levantamento historiográfico, apresenta a influência do pensamento religioso e das práticas nele fundamentadas, bem como a do desenvolvimento da medicina e da noção de normalidade, sobre a imagem social das pessoas cujos corpos apresentam alguma diferença funcional.

Palavras-chave: diversidade funcional; diferença; normalidade; pessoas com deficiência.

\section{Abstract}

The article offers a critical analysis of how the differences displayed by people with disabilities have been perceived and dealt with in the social, educational, political, and therapeutic realms from ancient times until recent decades, when changes have been observed in Brazil. Whatever the type or degree of disability, we now use the terms 'differently abled' and 'different abilities', reflecting a current trend in terminology that avoids placing emphasis on negative aspects. Based on a historiographic survey, the article indicates how religious thought and practices and the development of medicine and of the notion of normalcy have influenced the social image of people whose bodies are differently abled.

Keywords: differently abled; difference; normalcy; people with disability. 
$J$ á no título deste artigo depara-se o leitor com a expressão diversidade funcional, designação ainda incomum no campo da saúde pública. Diante da condição vulgarmente chamada de deficiência, a produção teórica sobre o tema, bem como a prática médica esbarram numa questão delicada e polêmica: a terminologia. Em regra, os termos utilizados para referir qualquer diferença funcional são impróprios, inadequados e, não raro, pejorativos. A evidência clara de que a terminologia é campo árido pode ser percebida quando simplesmente ela falha para designar - sem embaraço ou constrangimento alguma diferença funcional. E não é por falta de palavras, pois todos conhecemos uma variedade delas referente à condição culturalmente conhecida como deficiência, em suas mais diversas manifestações. Conhecemos também seus sinônimos, incluídos aqueles que se tornaram grosseiramente pejorativos, como aleijado e entrevado, ainda em uso no interior do país. Especificamente no âmbito da saúde, apesar da existência de uma classificação internacional oficial, até mesmo os médicos costumam tropeçar nos termos quando emitem laudos ou falam sobre o assunto com seus pacientes.

Em O normal e o patológico, Canguilhem (1978, p.101-102) afirma, com irretocável consistência, que a anomalia é fato biológico. E, nesse sentido, acrescentamos que a condição que costumamos chamar de deficiência também o é. Ou seja, a deficiência, qualquer que seja, é fato biológico de diferenciação física, sensorial, orgânica ou intelectual. Essa caracterização - emprestada de Canguilhem - é pertinente mesmo em relação à deficiência adquirida, cujas limitações decorrentes são contornadas pela reabilitação, pelo reaprendizado das funções alteradas ou perdidas, pelo uso de próteses ou por alguma adaptação desencadeada no próprio organismo. Na deficiência adquirida o fato biológico não existe por si só, posto que há fatores ambientais (na forma de acidentes diversos) concorrendo para o seu surgimento. Mas, ainda assim, é na dimensão orgânica que as modificações acontecem, ou, usando palavras de Canguilhem, na dimensão orgânica "o ser é capaz de instituir novas normas" (p.109). O fato biológico presente na deficiência produz, em algum grau, uma diferença funcional. Dessa forma, em vez de ineficiência e incapacidade - sentido literal de deficiência -, a condição deficiência é, de fato, uma diferença funcional.

Para quem lida diretamente com a diversidade funcional, sempre estiveram claros os aspectos negativos, discriminatórios, limitados e contraditórios da terminologia em uso. Sabe-se que a conceituação e a terminologia aplicadas às deficiências foram desenvolvidas inicialmente para atender a uma clientela que toma decisões sobre a vida das pessoas que apresentam alguma diferença funcional, a saber, a medicina, a seguridade social e a reabilitação (Pereira, 2006). Em termos práticos, a terminologia responsabiliza diretamente a pessoa por sua condição física ou orgânica, ao mesmo tempo que parece isentar a sociedade e o ambiente físico de qualquer responsabilidade ou participação, apesar da generalizada falta de meios sociais e ambientais para todos integrar de modo pleno. Por ironia, as chamadas pessoas com deficiência tornam-se limitadas exatamente naqueles pontos em que a sociedade e/ou o ambiente são excludentes em relação à diversidade funcional. A responsabilidade recai sobre a pessoa que apresenta diferença funcional quando se espera - ou se exige - que ela se reabilite, se 'normalize', se adapte a uma sociedade que, de fato, foi construída para atender àqueles que correspondem ao padrão de normalidade.

A proposição da expressão diversidade funcional (Palacios, Romañach, 2006) foi apresentada em janeiro de 2005 no Fórum de Vida Independente, na Espanha. Conscientes 
de que a linguagem produz, modifica e orienta o pensamento, algumas organizações de pessoas com diferença funcional têm investido em novos termos, com o intuito de implantar outra concepção acerca da condição a que costumeiramente nos referimos como deficiência. A proposta dos espanhóis é substituir termos pejorativos como deficiência, incapacidade, invalidez etc. pela expressão diversidade funcional. Surge, então, a designação 'mulheres e homens com diversidade funcional', em substituição a 'pessoa com deficiência' e seus correlatos. A deficiência torna-se, assim, uma diferença funcional. Aplicado o modelo ao coletivo - e considerando que as deficiências são muitas e diferentes entre si -, pessoas com deficiência são, portanto, pessoas com diversidade funcional, ou seja, que funcionam de forma diferente. Nas demais referências, de forma direta ou indireta, os termos, sem exceção, indicam que a pessoa funciona mal, não funciona, é incapaz de funcionar etc., destacandose, assim, os aspectos negativos como inerentes a tal condição.

A diversidade funcional sempre foi percebida, compreendida e tratada a partir de um conjunto de representações próprio da cultura ou da sociedade em que está inserida. O fundamento de tais representações é formado por padrões religiosos, familiares, sociais, econômicos e culturais, que compõem os ideais de forma, aparência e funcionamento de nosso corpo. Assim, cada cultura e cada época apresentam concepções próprias de diversidade funcional, englobando crenças ou mitos explicativos, bem como formas de tratamento da questão, o que resulta num leque de procedimentos e atitudes que variam entre segregação social, eliminação sumária, divinização, acolhimento ou indiferença. Independentemente da concepção de diferença funcional, dos rituais ou das formas de tratamento, ou mesmo do status social dessas pessoas em uma sociedade, a diferença funcional e tudo aquilo que a ela se vincula constituem partes integrantes daquela sociedade e daquela cultura, mesmo que nela a segregação ou a eliminação sejam práticas comuns. Surgem, assim, concebidos e reforçados pela cultura, os modelos tomados como referência para a aparência, a forma e o funcionamento do corpo.

\section{O modelo de homem-padrão nas narrativas da história}

Há relatos muito antigos a respeito da diversidade funcional. As datas são geralmente obscuras, mas as culturas remotas podem ser identificadas com alguma facilidade. Entre os povos antigos, caracteristicamente nômades, os deslocamentos de grupos humanos eram determinados pelos ciclos da natureza, cujas condições escapavam completamente ao controle do homem, podendo ser favoráveis num dia e desfavoráveis no seguinte. Sendo a diferença funcional uma contingência humana, acredita-se que ela existiu mesmo nos contextos primitivos de organização social. Devido à necessidade de constantes deslocamentos dos grupos nômades, era fundamental que cada um de seus membros pudesse cuidar de si e ainda colaborar com os demais. As pessoas com alguma diferença funcional dificilmente estariam aptas para corresponder a tais critérios de independência e cooperação. De acordo com Bianchetti (1998, p.28),

É indispensável que cada um se baste por si e ainda colabore com o grupo. É evidente que alguém que não se enquadra no padrão social e historicamente considerado normal, quer seja decorrente do seu processo de concepção e nascimento ou impingido na luta pela 
sobrevivência, acaba se tornando um empecilho, um peso morto, fato que o leva a ser relegado, abandonado, sem que isto cause os chamados "sentimentos de culpa" característicos da nossa fase histórica.

Vários autores mencionam a eliminação sumária de pessoas com diferença funcional na Antiguidade, especialmente na Grécia antiga (Bianchetti, 1998; Cavalcante, 2002; Kirk, Gallagher, 1987; Pessotti, 1984; Silva, Dessen, 2001). As crianças que nasciam com alguma deformidade física eram consideradas sub-humanas, e a eliminação era prática corriqueira (Pessotti, 1984). O relato mais antigo e preciso a esse respeito é encontrado na Política, obra clássica de Aristóteles, cujo texto contém várias recomendações do autor acerca do casamento e da educação dos filhos, sendo "dever do legislador garantir às crianças uma boa organização física". Aristóteles inclui algumas características dos pais, tais como idade e aspectos físicos, bem como os cuidados durante a gestação, que poderiam favorecer a saúde dos filhos e, por extensão, da sociedade. Sobre os recém-nascidos, o autor afirma: "com respeito a conhecer quais os filhos que devem ser abandonados ou educados; precisa existir uma lei que proíba nutrir toda criança disforme" (livro IV, cap.XIV). Os gregos valorizavam a perfeição e a estética do corpo, assim como as habilidades físicas para a guerra, a ginástica, os jogos e a dança. Se, ao nascer, uma criança não correspondesse aos ideais atléticos e estéticos, seria sumariamente eliminada.

É também da Grécia antiga a origem do termo estigma. Os gregos possuíam vasto conhecimento sobre recursos visuais, o que os levou a criar a palavra estigma para referir "sinais corporais com os quais se procurava evidenciar alguma coisa de extraordinário ou mau sobre o status moral de quem os apresentava" (Goffman, 1988, p.11). Os sinais eram feitos no corpo, utilizando-se instrumentos de corte ou aquecidos no fogo até ficarem em brasa, e serviam para alertar a sociedade de que o indivíduo era escravo, criminoso ou traidor e deveria ser evitado por ser pessoa marcada ou "ritualmente poluída" (Douglas, 1976). A marca, incluindo aí as condições físicas, indicava que o contato com tais pessoas não apenas deveria ser evitado, mas também poderia ser perigoso (p.15, 55).

A concepção de diferença funcional, na Grécia antiga, distingue-se daquela observada no Egito e na Palestina. Entre os gregos, o corpo era fundamental, pela importância dada à estética, aos ideais atléticos e às práticas belicistas, o que transformava qualquer diferença funcional em condição humilhante, indesejável, cuja eliminação era necessária. Ao mesmo tempo que, na Grécia, pessoas com diferença funcional eram eliminadas, no Egito elas chegaram a ser divinizadas (Cavalcante, 2002). Na Palestina, por sua vez, a concepção de diferença funcional foi influenciada por aspectos místicos e religiosos, e a presença de alguma diferença no corpo ganhou conotação semelhante ao estigma na Grécia, por ser considerada marca imposta ao corpo por alguma divindade, como punição por pecado cometido. Essa última concepção influenciou fortemente o Ocidente desde a Antiguidade, e, mesmo na atualidade, embora de forma sutil, a pessoa com alguma diferença funcional e quem lhe é próximo não raro ainda buscam explicações a partir de elementos religiosos ou sobrenaturais.

No início da era cristã, embora prevalecendo a relação entre pecado e diferença funcional, iniciativas de acolhimento começaram a substituir a eliminação sumária da diversidade funcional. Vários mosteiros e hospitais cristãos primitivos manifestaram preocupação com 
os cegos. Provavelmente o primeiro abrigo para cegos foi criado por são Basílio de Cesareia, iniciativa que remonta ao século IV. No século seguinte estabeleceram-se instalações semelhantes em diferentes locais, como Síria, Jerusalém, França, Itália e Alemanha (Telford, Sawrey, 1977).

Diferentemente de pessoas com outras diferenças funcionais, os cegos, apesar de discriminados, receberam tratamento especial, favorecimento devido a questões místicas, mas também de ordem prática. Cegos - é sabido - possuíam funções relevantes, servindo como guias em deslocamentos na escuridão e como memorizadores e transmissores de tradições tribais e religiosas. Foram reverenciados como adivinhos e profetas, sendo sua diferença percebida como graça divina. Embora ocasionalmente tal diferença foi considerada condição benigna, obtida por meio da graça divina, em outros contextos e com maior frequência ela também foi encarada como punição por pecados cometidos pelo próprio indivíduo ou por seus pais, caracterizando a diferença funcional visual como estigma sujeito a alguma forma de discriminação (Telford, Sawrey, 1977, p.467-468).

\section{Tempos sombrios para a diversidade funcional}

Durante a Idade Média, as explicações religiosas e místicas acerca da diversidade funcional tornaram-se ainda mais contundentes e severas. Naqueles tempos a Igreja estava no auge de sua influência, impondo seus dogmas tanto pela persuasão quanto pela força bruta. A diferença funcional mantinha seu caráter de fenômeno metafísico ou espiritual, ora como algo divino, ora como demoníaco, e o tratamento dispensado às pessoas com diferença funcional era determinado pela concepção em questão, variando entre maus-tratos e os mais variados tipos de tortura. Com a Inquisição a imperar a partir do século XIII - época em que os sinais de diferenças físicas e mentais eram interpretados como produto da união de uma mulher com o demônio -, muitas crianças com diferença funcional e suas respectivas mães foram levadas às fogueiras. Esse foi o destino de milhares de pessoas que apresentavam, no corpo, alguma diferença considerada anormal, ou que se comportavam de maneira tida como inadequada. Corpos e condutas que se destacassem por alguma diferença em relação ao padrão vigente eram imediatamente atribuídos a alguma ligação com o demônio (Bianchetti, 1998; Cavalcante, 2002; Schwartzman, 1999).

Ainda na Idade Média, a Igreja passou a acreditar que diversidade funcional e alma poderiam coexistir em um corpo. Assim, apesar da diferença - e ainda sujeitos à 'purificação pelas chamas' -, tais indivíduos passaram a ser ditos filhos de Deus. Essa nova concepção resultou na diminuição dos maus-tratos, das torturas e do abandono, e as pessoas com diversidade funcional começaram a ser acolhidas em instituições de caridade (Silva, Dessen, 2001). Com a nova 'condição espiritual', aqueles que não se enquadravam no modelo vigente de homem-padrão ganhavam o direito à vida, mas continuavam sendo estigmatizados, pois a diferença estampada no corpo ainda era interpretada como sinônimo de pecado (Bianchetti, 1998).

Essa mudança de concepção por parte da Igreja foi influenciada pelas Cruzadas, operações ao mesmo tempo religiosas e bélicas que mutilaram muitos religiosos e aventureiros. Para atender a essa inédita demanda social, Luís IV criou em Paris, em 1254, um asilo para acolher 
expedicionários que voltavam cegos dos campos de batalha (Telford, Sawrey, 1977). Embora muitos cruzados tivessem ambições pessoais, especialmente interesses econômicos e políticos, as Cruzadas eram caracterizadas como movimento religioso, uma guerra santa contra qualquer grupo considerado inimigo da Cruz, envolvendo até crianças numa marcha do sul da Europa à Itália, em 1212, fato que ficou conhecido como a Cruzada das Crianças (Cairns, 1988).

As mutilações são comuns em qualquer operação militar, e nas Cruzadas não foi diferente. Seria todavia contraditório para a Igreja afirmar que quem ficara cego durante a participação nas Cruzadas - portanto ao atender aos apelos da Igreja, na luta pela fé cristã - fora punido por algum pecado. As mutilações então ocorridas demonstraram que a diversidade funcional possui objetivamente outras causas que não as sobrenaturais, daí a atitude acolhedora da Igreja, criando instituições de amparo àqueles expedicionários. As Cruzadas ocorreram ao longo de cerca de dois séculos. As atitudes de acolhimento observadas naquele tempo não foram suficientes para mudar a concepção de diferença funcional, pois seus portadores continuavam sofrendo práticas como eliminação, segregação e acolhimento.

A menção à influência da Igreja não deve ser entendida como exclusiva do catolicismo. Martinho Lutero, o Reformador, considerado o pai do protestantismo, teria aconselhado um príncipe a afogar num rio um ser que ele, Lutero, vira e contra o qual lutara. Tratavase, segundo a descrição de Lutero, de uma criança que poderia ser confundida com uma criança normal, mas que não fazia outra coisa senão comer muito, tanto quanto um trabalhador do campo, defecar, babar e gritar muito quando era tocada. Como seu conselho não foi seguido, Lutero comprometeu-se a orar junto com os cristãos para que o demônio fosse expulso daquela criança (Pessotti, 1994).

\section{Uma tênue luz na Era das Luzes}

Entre o final do século XV e início do XVI, houve uma mudança nas concepções de homem, sociedade e mundo. O comércio se expandiu, novas terras foram descobertas e o mundo ganhou outras dimensões geográficas. As transformações desencadearam mudanças mais duradouras no campo da diversidade funcional. A concepção de diferença funcional, a partir de então, teve vinculação mais direta com o sistema econômico, e as pessoas que apresentavam diferenças funcionais passaram a ser avaliadas de acordo com sua capacidade produtiva.

Durante o século XVI, já sob a influência do antropocentrismo renascentista, a diversidade funcional começou a atrair o interesse de pessoas cujo pensamento ia além das justificativas sobrenaturais para tudo aquilo que não se podia explicar objetivamente. Surgiram assim os primeiros questionamentos acerca da origem sobrenatural da diferença funcional. Essa nova abordagem é atribuída ao pioneirismo de Cardano, médico e filósofo, e Paracelso, médico e alquimista, que, na esteira renascentista de retorno ao homem e a seu corpo, teriam pioneiramente tentado interpretar o comportamento de pessoas com diferença funcional a partir de parâmetros mais objetivos. Cardano e Paracelso contribuíram para o avanço do conhecimento acerca da diversidade funcional, questionando seu aspecto 
sobrenatural e considerando-a doença. A partir desse século as diferenças funcionais deixaram de pertencer exclusivamente ao campo de influência da Igreja e do sobrenatural, para se tornar objetos de estudo da medicina (Bianchetti, 1998; Mantoan, 1989; Silva, Dessen, 2001).

\section{A invenção da normalidade}

Com o avanço da medicina e as teorias de Isaac Newton, a concepção de diferença funcional passou a ter contornos muito diferentes daqueles conhecidos até então. A visão mecanicista do universo fez emergir um resultado desastroso para a diversidade funcional: como o corpo também passou a ser visto e tratado como máquina, as doenças, assim como as várias formas de diferença funcional, passaram a ser consideradas disfunções de algum componente dessa máquina. Com isso, a modernidade deixou para trás as questões espirituais e místicas, os demônios e as divindades, passando a ocupar-se de questões menos transcendentes, mais concretas e objetivas: diferença funcional, desde então, é disfuncionalidade, desvio e anormalidade (Bianchetti, 1998; Marques, 2001; Silva, Dessen, 2001).

A medicina acompanhou de perto o crescimento de todos os campos do conhecimento entre os séculos XVII e XVIII, época em que "a saúde e a doença disputavam o homem assim como o bem e o mal disputavam o mundo" (Canguilhem, 1978, p.77). No mesmo período o conhecimento acerca da diversidade funcional também se ampliou e surgiram várias concepções aplicadas tanto na institucionalização da diferença como no ensino especial (Silva, Dessen, 2001). A despeito do avanço do conhecimento observado no período, vários autores afirmam que, ao lado do suposto acolhimento, persistia a ambivalência caridade/castigo no processo de institucionalização (Caponi, 2000; Cavalcante, 2002; Kirk, Gallagher, 1987; Marques, 2001; Silva, 2003).

Ainda nesse período, vale destacar a vigência da chamada Lei dos Pobres, na Inglaterra, o mais antigo e explícito exemplo de coerção compassiva ou ambivalência caridade/castigo de que se tem notícia (Caponi, 2000). No início do século XVIII, 'pobre' era usado para referir uma variedade de condições sociais. Aplicava-se aos pobres propriamente ditos, mas englobava também outras condições específicas, incluindo as pessoas com diversidade funcional. As circunstâncias particulares que distinguiam uma viúva de um doente ou um órfão de uma pessoa com diferença funcional não recebiam a menor atenção, conforme relata Giddens (2002, p.146): “O uso do termo 'pobre' no começo do século XVIII abrangia uma variedade de condições sociais. As discussões e a legislação sobre os pobres incluíam viúvas, órfãos, doentes, velhos, deficientes e insanos sem fazer clara distinção entre eles. A necessidade moralmente definida, em vez das circunstâncias especiais que a produziam, era a característica identificadora" (grifo meu).

Conforme Caponi (2000), a ambiguidade permeava todos os projetos filantrópicos daquele período. As supostas atitudes de acolhimento eram apresentadas como assistência caridosa dirigida às pessoas necessitadas, entretanto funcionavam, ao mesmo tempo, como eficiente dispositivo de coerção social. O indivíduo com alguma diferença funcional figurava na lista, dessa feita, como pobre necessitado, alguém que dependia da caridade alheia, que merecia os cuidados especiais oferecidos pelas instituições de caridade. Tal processo de 
acolhimento e proteção implicava, obviamente, segregação e isolamento social (Kirk, Gallagher, 1987; Silva, 2003).

A época em questão foi crucial para a formação discursiva da invalidez, da incapacidade e, consequentemente, da inferioridade das pessoas com alguma diferença funcional. As mesmas instituições de caridade que acolhiam também reforçavam o estigma daquelas pessoas, ao defini-las como sujeitos da caridade alheia, com todas as implicações sociais produzidas por essa condição. Em outras palavras, as consequências sociais das instituições de amparo à diversidade funcional constituíram demonstração pública da invalidez, marca social que promoveu o fortalecimento do preconceito e da discriminação. Os efeitos sociais das instituições de caridade foram marcantes e profundamente negativos para a questão da diferença funcional, a ponto de, ainda hoje, eles não estarem plenamente eliminados.

Ainda no século XVIII, outros fatores influenciaram a concepção de diferença funcional. Cabe destacar a Revolução Industrial e todos os seus desdobramentos socioculturais. A ideia de invalidez e incapacidade, então, já estava fortemente atrelada à diversidade funcional. Com a Revolução Industrial, a produtividade tornou-se o combustível a mover o crescimento das indústrias e do capital, e, em decorrência, os trabalhadores tiveram que corresponder a essa demanda. O novo modelo de produção trouxe mudanças significativas, que abrangeram desde as relações familiares até a estabelecida com o trabalho propriamente dito. O indivíduo passou a ser valorizado e reconhecido socialmente conforme o que pudesse produzir. O novo conceito de trabalho excluiu sumariamente as pessoas com diferenças funcionais, que desde antes já carregavam consigo o estigma da invalidez e da incapacidade. Essa condição de inferioridade social atrelada à diversidade funcional seria ainda mais reforçada nas décadas seguintes.

A Revolução Industrial não apenas excluiu, mas também produziu pessoas com diferença funcional. Foi, na verdade, um processo que durou décadas. A nova concepção de trabalho implantou-se aos poucos, e os parques industriais se foram paulatinamente expandindo e aperfeiçoando. As condições de trabalho eram extremamente precárias, sem qualquer mecanismo de segurança, e os operários, massacrados pelas longas jornadas de trabalho. Em tais condições, sobretudo com a falta de segurança, certamente havia muitos acidentes, entre eles alguns cujas consequências restringiam o desempenho esperado dos trabalhadores. Desconhecemos qualquer registro histórico a esse respeito, entretanto, com base na atual ocorrência de acidentes, mesmo em indústrias mais sofisticadas e com equipamentos de segurança adequados, concluímos que, nas condições em que as primeiras indústrias operavam, elas não apenas excluíram, mas também produziram diferença funcional.

Outro dado que reforça a argumentação é o surgimento de sistemas de reabilitação, que, a princípio, apareceram como variação das instituições de proteção ou de caridade. São dessa época também as primeiras manifestações dos profissionais de saúde, no sentido de estabelecer uma classificação das doenças (Amiralian et al., 2000; Silva, 2003), bem como o início dos estudos referentes à diversidade funcional. Duas questões de suma importância podem ser levantadas aqui: a primeira é que esses estudos tinham como ponto de partida e modelo de funcionamento as pessoas consideradas normais; a segunda diz respeito aos cuidados médicos, que muitas vezes tinha como objetivo proteger os de fora, aqueles não acometidos por problemas físicos, muito mais do que tratar os de dentro, que 
precisavam de algum atendimento. Giddens (2002, p.150) afirma: “O hospital também é um lugar onde aqueles que foram desqualificados da participação nas atividades sociais ortodoxas são segregados ... [e] o surgimento de uma esfera separada de tratamento médico, focado em pessoas com 'problemas físicos' distintos, é parte dos mesmíssimos processos que criaram outras organizações carcerárias".

Na Revolução Industrial a medicina já possuía uma concepção de diferença funcional, posteriormente consolidada; o padrão de normalidade já era referência tanto para o discurso quanto para a prática médica. De acordo com Clapton e Fitzgerald (2002), naquele período a diversidade funcional era considerada pela medicina sofrimento físico. A concepção estava ancorada predominantemente nos discursos médicos e científicos, cujas determinações tinham caráter irretocável - o que lembra, inevitavelmente, a autoridade da Igreja e, sobretudo, a purificação pelas chamas -, em decorrência da força e prepotência do discurso científico naquele momento. As pessoas com diferença funcional não foram absorvidas pelo mercado de trabalho emergente, e, em parte, a concepção médica da época contribuiu para essa segregação, assim como para a imagem social negativa da diversidade funcional: eram tratadas como massa de pessoas inválidas e incapazes para o trabalho.

\section{A medicalização da educação: o surgimento da educação especial}

Aparentemente a educação configura campo distinto da medicina. O olhar mais acurado, porém, percebe uma interface entre os dois campos, ainda mais clara quando se trata de educação especial, segmento da educação que surgiu fortemente marcado pelo viés da reabilitação e da normalização das pessoas com diferenças funcionais. Suas primeiras iniciativas datam do século XVIII, quando as instituições se diversificaram, passando também a educação por esse processo.

Algumas instituições voltadas para a educação de pessoas com diferença funcional tinham como motivação a caridade, mas outras tantas não estavam contaminadas por esse viés. Destacam-se aqui dois segmentos influentes, na educação especial. O primeiro envolveu religiosos como o abade De l'Épée (1710-1789), na França, e o pastor Samuel Heinicke (1723-1790), na Alemanha, ambos dedicados à educação de surdos. O segundo era composto por vários nomes ligados à medicina, uma espécie de 'tradição' iniciada no século XVIII e que se estendeu até o XX. Vejamos alguns exemplos: Jean Itard (1775-1838) era médico e filósofo; Édouard Claparède (1873-1940) estudou medicina; Maria Montessori (1870-1952) era educadora e médica; Vygotsky (1896-1934) passou pela medicina antes de formar-se em direito e interessar-se pelo estudo dos processos psicológicos superiores, como o pensamento e a linguagem.

Na primeira escola para crianças surdas, na França, o abade De l'Épée as educava por meio de sinais manuais. Na escola alemã, Samuel Heinicke ensinava por métodos de comunicação oral. Em decorrência, por volta de 1800, havia duas escolas de pensamentos opostos em relação à melhor maneira de lecionar para crianças surdas: oral ou gestual (Kirk, Gallagher, 1987; Telford, Sawrey, 1977). Passados mais de dois séculos a divergência persiste, e a base que sustenta a polêmica é a suposta normalidade da comunicação oral, apesar da eficácia comprovada e, sobretudo, da preferência dos próprios surdos pelo sistema 
francês, aperfeiçoado ao longo do tempo e considerado a matriz da Língua Brasileira de Sinais (Libras).

O primeiro programa sistemático de educação especial foi desenvolvido em 1800 por Jean Itard, nome bastante conhecido nesse campo (Cavalcante, 2002). Nos anos seguintes a diversidade funcional seria contemplada sob vários aspectos, em especial na educação. Só no século XIX, entretanto, observou-se atitude de responsabilidade pública em relação às necessidades das pessoas com diferença funcional (Silva, Dessen, 2001).

Em curto espaço de tempo a diversidade funcional tornou-se objeto da atenção de vários educadores. As noções de proteção e normalização, entretanto, permaneciam latentes no formato de algumas instituições. Em 1817 foi criada a primeira de caráter residencial para crianças surdas em Hartford (Connecticut, EUA), denominada American Asylum for Education and Instruction, depois American School for the Deaf. A instituição parece ter perdido seu caráter de asilo na segunda metade do século XX (Kirk, Gallagher, 1987).

Esse modelo residencial inspirou, 12 anos mais tarde, instituição semelhante para crianças cegas. O New England Asylum for the Blind foi fundado em 1829, na cidade de Watertown (Massachusetts, EUA), tendo posteriormente seu nome modificado para Perkins School for the Blind. Naquele mesmo ano, conforme Telford e Sawrey (1977), outro fato transformou profundamente a vida das pessoas cegas: Louis Braille, jovem estudante cego, modificou um código militar usado para comunicação noturna, a fim de ser utilizado por cegos. Considerado o criador do método amplamente utilizado no mundo inteiro, Braille de fato abriu novas portas para as pessoas cegas, e sua brilhante iniciativa é mundialmente reconhecida.

No Brasil, o Instituto Benjamim Constant (IBC), reconhecido no campo da educação de cegos, foi criado em 1854 por decreto de d. Pedro II. Sua inauguração oficial ocorreu em 17 de setembro daquele mesmo ano, com o nome de Imperial Instituto dos Meninos Cegos, que vigorou até 1891, quando foi inaugurado o prédio onde funciona atualmente, no bairro da Urca, no Rio de Janeiro. A iniciativa imperial estendeu-se aos surdos, com a criação do Imperial Instituto de Surdos Mudos em 26 de setembro de 1857, depois Instituto Nacional de Educação de Surdos (Ines). Essas instituições, de modo geral, ofereciam algum treinamento para os residentes. Destacava-se, sobretudo, o ambiente pensado e preparado para proteger e reabilitar - em outras palavras, normalizar - pessoas com diferenças funcionais. Não havia qualquer investimento operacional ou técnico que pudesse favorecer a autonomia dos acolhidos. Também não havia suporte psicológico, pois a psicologia ainda era embrionária em finais do século XIX. De fato, muitos residentes tornaram-se dependentes das instituições por toda a vida, conforme relatos de Kirk e Gallagher (1987). A filosofia de trabalho aparentemente diferia muito das instituições religiosas mencionadas, embora se preservassem a atitude protetora e a impossibilidade de condição social diferente daquela vivida nas instituições residenciais. Podendo ser chamadas de 'filhas' das instituições de caridade, aprimoraram o sistema de acolhimento e fortaleceram todos os estigmas e preconceitos existentes.

As chamadas classes especiais em escolas públicas, destinadas a pessoas não vinculadas a esses espaços residenciais, representam outra forma de institucionalização da diversidade 
funcional. De acordo com Kirk e Gallagher (1987), elas aparecem na segunda metade do século XIX, nos Estados Unidos, tendo a primeira sido criada em 1869, em Boston, para o atendimento de crianças surdas e, provavelmente, também pioneira no funcionamento diário.

Segundo Scliar (1999), a educação especial conserva um olhar iluminista sobre a identidade de seus sujeitos. Constrói seu discurso e suas práticas pedagógicas baseada em oposições como normalidade/anormalidade, racionalidade/irracionalidade e completude/incompletude. Submetidos a esse modelo, os sujeitos são homogeneizados, infantilizados e, ao mesmo tempo, naturalizados, valendo-se de representações sobre aquilo que estaria faltando em seus corpos, suas mentes e suas linguagens. Dessa forma, o discurso e a prática do ideal de normalidade se inscrevem na escolarização complementando uma prática surgida antes mesmo da chamada educação especial: a normalização do corpo e da vida das pessoas que compõem a diversidade funcional.

\section{Novos ares para a diversidade funcional}

O século XX trouxe também muitas e variadas mudanças. Algumas foram de fato efetivas, outras, meramente cosméticas. Teoricamente o século pode ser retratado como o da integração, especialmente em sua última metade, quando todos os segmentos sociais foram conclamados a integrar pessoas com as mais variadas diferenças funcionais. A primeira iniciativa em nível internacional foi patrocinada pela Organização das Nações Unidas (ONU), com a aprovação da Declaração dos Direitos das Pessoas Deficientes, em 1975. Com esse documento a ONU lançava internacionalmente o termo 'pessoa deficiente', definido no primeiro artigo da referida Declaração: “A expressão 'pessoa deficiente' referese a qualquer pessoa incapaz de assegurar por si, total ou parcialmente, as necessidades de uma vida individual e/ou social normal, em decorrência de alguma deficiência congênita ou não, em suas capacidades físicas ou mentais" (UN, 1975; tradução livre).

No Brasil particularmente, até a década de 1970 todas as questões relativas à diversidade funcional eram orientadas por profissionais ligados à área médica, os chamados especialistas, cujo atendimento era geralmente feito em instituições de saúde ou reabilitação (Bieler, 1990; Saeta, 1999). Na abordagem típica do período, uma diferença funcional era percebida no lugar da pessoa (Saeta, 1999).

De acordo com Bieler (1990), na segunda metade do século XX surgiram várias instituições no país com finalidades variadas, mas todas elas marcadas pela política de proteção ou paternalista, entre elas a Federação Nacional das APAEs (1962), a Federação Nacional das Sociedades Pestalozzi (1970) e a Federação Brasileira de Instituições de Excepcionais (1974).

No final da década de 1970 a ONU iniciou movimento mundial que culminou na realização do Ano Internacional das Pessoas Deficientes (AIPD), em 1981. Como parte desse movimento, decretou, em 1983, a Década das Pessoas Portadoras de Deficiência (19831992), buscando com isso dar visibilidade internacional às questões ligadas à diversidade funcional. Na época foi elaborado um Programa de Ações Mundiais Para as Pessoas Portadoras de Deficiência, visando à unificação internacional das práticas. 
Engajados no movimento iniciado pela ONU, em 1979 vários grupos organizados começaram a pensar e discutir a questão da diversidade funcional no Brasil. Um detalhe fundamental caracterizou essa mobilização: surgia ali um movimento inédito no país, conduzido pelas próprias pessoas com diferenças funcionais, sem qualquer interferência de técnicos e especialistas; uma mobilização brasileira em torno das questões ligadas à diversidade funcional (Bieler, 1990) que representou, também, ruptura com a percepção medicalizada da diferença funcional, promovendo pessoas da inalterável condição de pacientes para a posição de sujeitos e cidadãos.

Em 1984 a mobilização de pessoas com diversidade funcional já era chamada de movimento e contava com estrutura organizada, compatível com essa designação. A partir da atuação política desse movimento, e também sob a influência do Ano Internacional das Pessoas Deficientes, criaram-se naquele ano várias entidades comprometidas com a diversidade funcional, entre elas a Federação Nacional de Educação e Integração dos Surdos (Feneis), o Movimento de Reintegração dos Hansenianos (Morhan) e o Conselho Brasileiro de Entidades de Pessoas Deficientes. Tendo conquistado reconhecimento político, representavam várias pequenas associações locais (esportivas, educacionais, assistenciais etc.) espalhadas pelo país e em funcionamento desde a década de 1970, mas totalmente desarticuladas entre si. A mobilização em torno do Ano Internacional possibilitou a articulação e o surgimento de um movimento para a integração da diversidade funcional em todos os segmentos sociais (Bieler, 1990; Saeta, 1999).

Em cerca de cinco anos, de 1979 a 1984, ganhou visibilidade social e política uma mobilização nacional de pessoas com diferença funcional - historicamente tuteladas pelo Estado e pelas instituições médicas e assistenciais - motivadas pelo lema do Ano Internacional: "Plena participação e igualdade". Conforme Bieler (1990), dois anos depois, a liderança envolvida naquela mobilização concebeu a Coordenadoria Nacional Para a Integração das Pessoas Portadoras de Deficiência (Corde), criada oficialmente no ano seguinte por decreto do governo federal, aprovado pelo Congresso Nacional. Vinculada ao então Ministério da Ação Social, suas atribuições incluíam a normatização, articulação e coordenação das ações envolvendo a diversidade funcional em nível federal.

\section{Considerações finais}

Nestas últimas décadas, pessoas com diversidade funcional conquistaram espaço antes inexistente na sociedade, nas políticas públicas, na geografia urbana, no mercado de trabalho e na mídia. De fato, para quem participou diretamente no processo as conquistas são visíveis, notáveis, mas sob muitos aspectos possuem caráter de mera concessão feita a um grupo minoritário, muito mais do que de cidadania. Em todos os segmentos sociais, por onde deveriam transitar livremente pessoas com diferença funcional, ainda persistem barreiras visíveis e preconceito, no mínimo, velado. Isso inclui os campos da saúde, educação, mercado de trabalho, turismo e lazer, transporte e equipamentos públicos.

Sob certos aspectos, as últimas décadas representam um cenário paradoxal: se levarmos em conta o passado, especialmente o mais remoto, a situação atual é substancialmente mais acolhedora e inclusiva, com espaço para a diversidade funcional em praticamente 
todos os segmentos da sociedade. Há, entretanto, muito a fazer para que cidadania, reconhecimento e respeito pela diversidade funcional sejam a regra geral e não a exceção. Organismos internacionais como a ONU, a Organização das Nações Unidas Para a Educação, a Ciência e a Cultura (Unesco) e a Rehabilitation International estão empenhados em eliminar todas as formas de discriminação ainda existentes em diversos países e alcançar uma sociedade realmente justa e igualitária.

Além dos esforços e conquistas, no campo dos direitos humanos, envolvendo a sociedade, governos e organismos internacionais, um segmento paralelo também tem promovido profundas mudanças nas últimas décadas, sobretudo em anos recentes, atraindo avidamente a atenção da sociedade e das pessoas com diversidade funcional. Trata-se do campo médico-científico. Ao que tudo indica, as pesquisas estão construindo um futuro livre das antigas ditas deficiências. A diversidade funcional tem mudado suas feições nestas últimas décadas com a sofisticação dos recursos e materiais disponíveis para corrigir, minimizar e até eliminar as várias diferenças funcionais. Essas inovações são bem-vindas! E o são por vários motivos, desde a melhoria da qualidade de vida de muitas pessoas, até a eliminação de um antigo desconforto experimentado em face da diversidade funcional.

O histórico modelo de homem-padrão influencia - e, muitas vezes, mobiliza! - o interesse médico-científico, social e, por extensão, das pessoas com diversidade funcional. Respeitados os direitos, a necessidade, a liberdade e o desejo consciente e manifesto de uma pessoa com alguma diferença funcional, qualquer inovação que aprimore sua condição funcional é benéfica e bem-vinda. Se, diferentemente, a inovação for apenas uma normalização hightech, estaremos reeditando antigas formas de discriminação e segregação em nome de uma pseudociência e do suposto bem-estar das pessoas que compõem a diversidade funcional.

\section{REFERÊNCIAS}

AMIRALIAN, Maria L.T. et al. Conceituando deficiência. Revista de Saúde Pública, São Paulo, v.34, n.1. Disponível em: http://www.scielo.br/scielo.php?script=sci arttext\&pid=S0034-89102000000100017\&lng =en\&nrm=iso $>$. Acesso em: 15 jun. 2005. 2000.

ARISTÓTELES.

Política. São Paulo: Martin Claret. 2003.

BIANCHETTI, Lucídio.

Aspectos históricos da apreensão e da educação dos considerados deficientes. In: Bianchetti, Lucídio; Freire, Ida Mara (Org). Um olhar sobre a diferença. Campinas: Papirus. p.21-51. 1998.

BIELER, Rosangela Berman.

Ética e legislação: os direitos das pessoas portadoras de deficiência no Brasil. Rio de Janeiro: Rotary Club. 1990.

CAIRNS, Earle E.

O cristianismo através dos séculos: uma história

da Igreja cristã. São Paulo: Vida Nova. 1988.
CANGUILHEM, Georges.

O normal e o patológico. Rio de Janeiro: Forense. 1978.

CAPONI, Sandra.

Da compaixão à solidariedade: uma genealogia da assistência médica. Rio de Janeiro: Fiocruz. 2000.

CAVALCANTE, Fátima Gonçalves.

Pessoas muito especiais: a construção social do portador de deficiência e reinvenção da família. Tese (Doutorado) - Escola Nacional de Saúde Pública, Fiocruz, Rio de Janeiro. 2002.

CLAPTON, Jayne; FITZGERALD, Jennifer. The history of disability: a history of 'otherness'. New Renaissance Magazine, v.7, n.1. Disponível em: http://www.ru.org/humanrights/the-history-of-disability-a-history-ofotherness.html. Acesso em: 9 out. 2005. 2002.

DOUGLAS, Mary.

Pureza e perigo. São Paulo: Perspectiva. 1976. 
GIDDENS, Anthony.

Modernidade e identidade. Rio de Janeiro: Jorge Zahar. 2002.

GOFFMAN, Erving.

Estigma: notas da manipulação da identidade deteriorada. Rio de Janeiro: LTC. 1988.

KIRK, Samuel A.; GALLAGHER, James J. Educação da criança excepcional. São Paulo: Martins Fontes. 1987.

MANTOAN, Maria Thereza Egler. Compreendendo a deficiência mental. São Paulo: Scipione. 1989.

MARQUES, Carlos Alberto.

A construção do anormal: uma estratégia de poder. Núcleo de Educação Especial - NESP. Disponível em: http://www.profala.com/ artpsico32.htm. Acesso em: 24 maio 2005. 2001.

PALACIOS, Agustina; ROMAÑACH, Javier. El modelo de la diversidad: la bioética y los derechos humanos como herramientas para alcanzar la plena dignidad en la diversidad funcional. Madrid: Diversitas. 2006.

PEREIRA, Raimundo J.

Anatomia da diferença: uma investigação teórico-descritiva da deficiência à luz do cotidiano. Tese (Doutorado) - Escola Nacional de Saúde Pública, Fiocruz, Rio de Janeiro. 2006.

PESSOTI, Isaias.

Deficiência mental: da superstição à ciência. São Paulo: Edusp. 1984.
SAETA, Beatriz Regina Pereira.

O contexto social e a deficiência. Psicologia: Teoria e Prática, São Paulo, v.1, n.1, p.51-55. 1999.

SCHWARTZMAN, José Salomão.

Histórico. In: Schwartzman, José Salomão (Org.). Síndrome de Down. São Paulo: Mackenzie. p.3-15. 1999.

SCLIAR, Carlos B.

A surdez: um olhar sobre as diferenças.

Porto Alegre: Mediação. 1999.

SILVA, Lorena Dantas da.

Corpo e deficiência. Par'a'iwa, João Pessoa, n.3. Disponível em: http://www.cchla.ufpb.br/ paraiwa/03-dantasdasilva.html. Acesso em: 9 nov. 2005. 2003.

SILVA, Nara Lima Pereira; DESSEN, Maria Auxiliadora.

Deficiência mental e família: implicações para o desenvolvimento da criança. Psicologia: Teoria e Pesquisa, Brasília, v.17, n.2, p.133-141. 2001.

TELFORD, Charles T.; SAWREY, James, M. $O$ indivíduo excepcional. Rio de Janeiro: Guanabara. 1977.

UN.

United Nations. Declaration on the Rights of Disabled Persons. Official records of the General Assembly, Thirtieth Session, supplement $n .34$ (A/ 10034), proclamada pela resolução 3447 (XXX) da Assembleia Geral em 9 de dezembro de 1975. Disponível em: http://www.unhchr.ch/html/menu 3/b/72.htm. Acesso em: 28 out. 2007. 1975.

\section{$\rightarrow \rightarrow \rightarrow<<<$}

